\title{
BEHAVIOUR AND IMPACT OF LEAKAGE IN VACUUM GRIPPING SYSTEMS
}

\author{
David Straub* \\ Graduate School of Excellence advanced Manufacturing Engineering in Stuttgart (GSaME), Universität Stuttgart, \\ Nobelstraße 12, 70569 Stuttgart, J. Schmalz GmbH, Johannes-Schmalz-Straße 1, 72293 Glatten \\ * Corresponding author: Tel.: +49 7443 2403470; E-mail address: david.straub@gsame.uni-stuttgart.de
}

\begin{abstract}
Leakage in a vacuum system causes the pressure to rise if it is not compensated like in case the supply energy carriers fail. This leads to the workpiece to be dropped. So in order to design vacuum gripping systems that can withstand a failure of the supply energy carriers over a predefined amount of time, it is crucial to know the influences and effects of leakage. In previous examinations the behavior of leakage has been examined on the basis of a closed fluidic reservoir with a hole in its wall. But the only impacts taken into account here are the volume of the reservoir, the diameter of the hole and the pressure difference. Whereas when it comes to vacuum gripping systems, the leakage has significantly more influencing factors as it is neither a single component nor a closed system. In vacuum gripping systems leakage mostly occurs at the interface between the suction cups and the workpiece. So in this contribution the focus is on the impact of the properties of those components, and how the variation of these properties affects leakage. To achieve this, a theoretical description is done based on the aforementioned research, which is expanded in order to the relevant characteristics of a vacuum gripping system. After that the description is evaluated on a test bench. The goal is to be able to make a statement about the leakage rate for a vacuum gripping system composed of standard components. This can then be used in the design process of such gripping systems, which have to fulfil the requirement of compensating leakage in case the energy supply fails.
\end{abstract}

Keywords: vacuum gripping systems, leakage

\section{INTRODUCTION}

Current design methods for vacuum gripping systems mostly focus on load transfer or selection of gripping points (c.f. e.g. [1-5]). They do not take into account a possible failure of the supply energy carriers. Especially in cases where dropping the workpiece can result in severe damage knowledge about leakage is crucial. This occurs for example in special human-robot collaboration applications where extraordinary heavy objects like batteries for vehicles with a hybrid powertrain are handled [6]. Dropping these can harm bystanders on one hand through their mass that can be above $100 \mathrm{~kg}$, and on the other hand through an exothermic chemical reaction that is caused by the drop.

In order to avoid that, knowledge about the impacts and effects of leakage is crucial.

\section{STATE OF THE ART}

Since a vacuum system consists of different components which have to be sealed to each other, so-called leaks can occur. They cause a gas inflow and can have different geometric characteristics [7]. These occur in vacuum gripping systems, when there is no completely closed sealing lip. This incomplete seal can be caused, for example, by uneven and rough workpiece surfaces [8]. The shape of the suction cup can also influence the leakage [9]. In general, the gas inflow $I_{E}$ into a vacuum system can be divided into several inflow components:

$I_{E}=I_{L}-I_{D}-I_{P}-I_{V}$

These are described as follows [10]:

- $I_{L}$ describes the inflow due to geometrical openings between the vacuum system and the environment. 
- $I_{D}$ describes the gas flow that occurs due to induced or thermal desorption, the process by which atoms or molecules on the surface of a solid enter the gas phase.

- $I_{P}$ describes the gas flow through completely dense parts (so-called permeation), a diffusion process due to a pressure gradient.

- $I_{V}$ describes the process flow that occurs in the vacuum system due to a vacuum technology process such as sublimation or evaporation of substances under vacuum.

The leakage $I_{L}$ due to openings between the vacuum system and the environment (in particular at the contact area of workpiece and suction cup) can be divided into three categories (cf. Figure 1) [11].
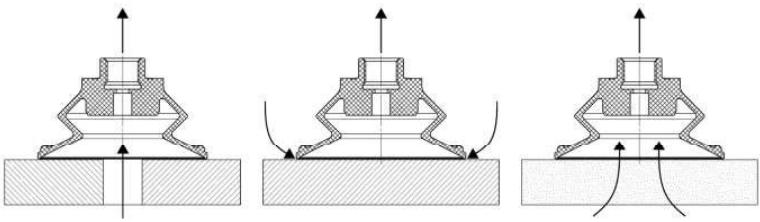

Figure 1: Three categories of leakage in vacuum gripping systems according to [11]

First order leakage (left) occurs within the suction surface at an opening in the workpiece. This is the case, for example, with perforated sheets. The second order leakage (middle) results from leaks between the contact surface of the suction cup and the workpiece. This can occur, for example, with uneven workpieces such as checker plates. Consequently, the surface roughness of the workpiece has an influence on the leakage $[12,13]$. Third order leakage (right) is due to air permeability of the workpiece, for example with wood or cardboard. This means that this type of leakage occurs continuously with these materials. The inflow component can be described as [14]:

$I_{L}=V \cdot \frac{d p}{d t}+p \cdot \frac{d p}{d t}$

Assuming that the product of pressure $p$ and volume $V$ changes, this results in [15]:

$I_{L}=\frac{\Delta(p \cdot V)}{\Delta t}$

If the volume is constant it results in:

$I_{L}(t)=V \cdot \frac{d p}{d t}$

With this correlation it is possible to determine the pressure rise $\Delta p$ at a known volume $V$. Since the increase in pressure is caused by an opening between the vacuum system and the environment, and thus a so-called leak is present, the inflow is constant over time $[10,14$, 16]:

$I_{L}(t)=V \cdot \frac{\Delta p}{\Delta t}=$ const.

The leakage can be described as follows:

$L=\frac{I_{L}}{V}=\frac{\Delta p}{\Delta t}=$ const.

This allows the leakage to be determined by measuring the pressure increase over time (so called pressure rise method) $[17,18]$. However, the constancy only applies to a certain pressure range. When the vacuum generator is switched off and the temperature is constant, the following applies according to (5):

$$
t=\int_{p_{2}}^{p_{1}} \frac{V}{I_{L}} d p
$$

Thereby the pressure $p$ in the system ranges below the critical pressure $p_{c r}$. Here the gas flow is constant. The critical pressure $p_{c r}$ is decribed by [19]:

$\frac{p_{c r}}{p_{0}}=\left(\frac{2}{\kappa}\right)^{\frac{\kappa}{\kappa-1}}$

As soon as the critical pressure $p_{c r}$ is exceeded the the inflowing gas flow decreases with increasing pressure. In general, the relationship between time and pressure over the entire vacuum range can be described as follows [19]:

$t=6,42 \cdot 10^{-2} \frac{V}{d^{2}} \cdot\left[\chi\left(\frac{p}{p_{0}}\right)-\chi\left(\frac{p_{\text {end }}}{p_{0}}\right)\right]$

Depending on the application, a certain leakage can also be deliberately permitted. The prerequisite for this, however, is that the vacuum generator ensures a sufficiently low pressure despite leakage [21]. Measures to reduce or compensate for leakage are the use of suction cups with a smaller circumference or more powerful vacuum generators [8, 22].

\section{ANALYSIS OF THE BOUNDARY CONDITIONS}

The following applies to the vapor pressure of water $p_{w}^{s}[20]$ :

$p_{w}^{S}(T)=p_{d} \cdot e^{17,2799-\frac{4102,99}{T+237,431}}$

with $p_{d}=6,11657 \mathrm{mbar}$ and the range of $\mathrm{T}$ defined as $0,01^{\circ} \mathrm{C} \leq T \leq 60^{\circ} \mathrm{C}$. For the reference temperature of $20^{\circ} \mathrm{C} p_{w}^{s}$ can be determined:

$p_{w}^{s}=23,4 m b a r$ 
This is below the pressure range of vacuum handling systems which is between 100 and $900 \mathrm{mbar}$ [1]. This means the influence of desorption $I_{D}$ does not have to be considered. The order of magnitude of the inflow component $I_{P}$ is even smaller [10]. Since no vacuumtechnical process takes place in the vacuum gripper, the inflow component $I_{V}$ does not occur here. From (9) the relationship between the time $t$ and the pressure after completion of the evacuation process $p_{\text {end }}$ to the pressure $p$ increasing due to leakage in a closed container with a circular opening having the diameter $d$ is known. The calculation factor $\chi$ is determined by:

$$
\chi\left(\frac{p}{p_{0}}\right)=\left\{\begin{array}{l}
\frac{p}{p_{0}} \text { for } 0<p \leq p_{c r} \\
\tilde{\chi} \text { for } p_{c r}<p \leq 1000 \mathrm{mbar}
\end{array}\right.
$$

For the calculation factor $\chi$ over the pressure ratio $p / p_{0}$ see Figure 2 .

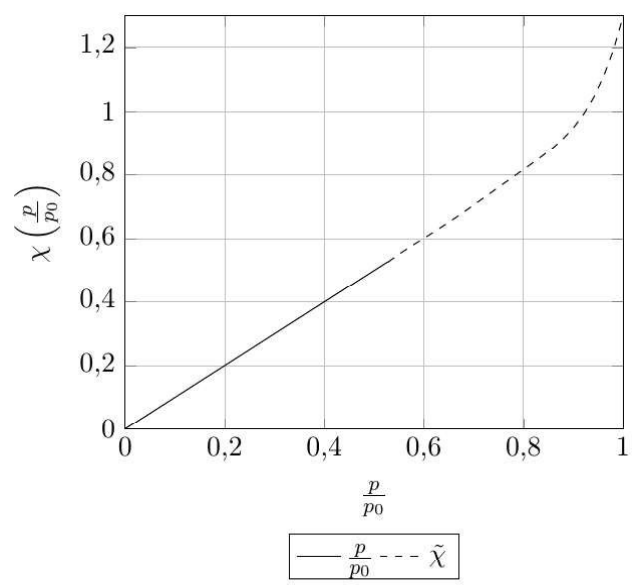

Figure 2: pressure calculation factor over pressure ratio for pressure increase in a closed container with a defined leak

Whereby according to (8) $p_{c r}=528 \mathrm{mbar}$. The linear relationship therefore applies in the range $p<528 m b a r$. If the function $\chi\left({ }^{p} / p_{0}\right)$ is examined more closely, the area $p \leq 800 \mathrm{mbar}$ is approximately linear (c.f. Figure 3) with the following correlation:

$\tilde{\chi}\left(\frac{p}{p_{0}}\right)=1,025 \frac{p}{p_{0}}$

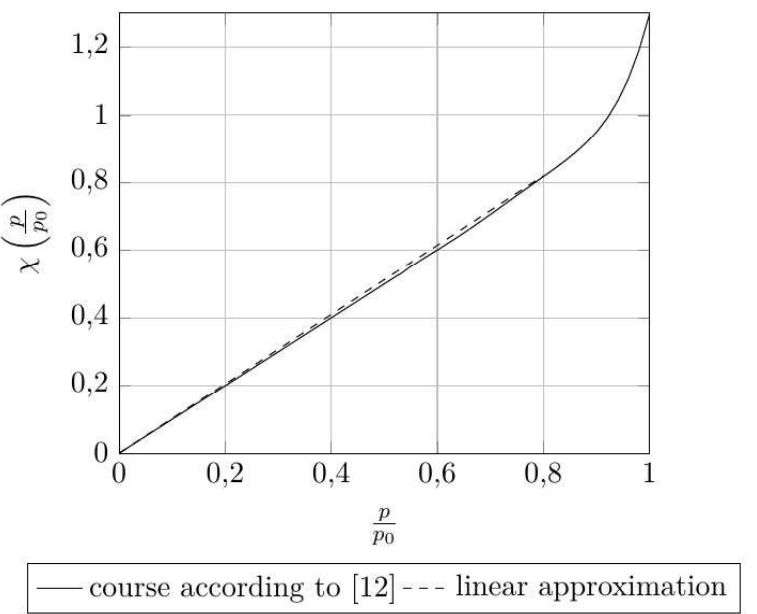

Figure 3: linear approximation of the calculation factor over pressure ratio for pressure increase in a closed container with a defined leak

According to the magnitude of pressure increase over time the leakage can be assigned to different states of the vacuum gripping system. Table 1 shows the different states of vacuum gripping systems depending on leakage for suction-tight sheets [23].

Table 1: different states of vacuum gripping systems depending on leakage

\begin{tabular}{lcc}
\hline system state & leakage in $\frac{\mathrm{mbar}}{\mathrm{s}}$ & holding time in s \\
\hline tight & $<67$ & $>6$ \\
low leakage & $67 . .133$ & $3 . .6$ \\
heavy leakage & $134 . .200$ & $2 . .3$ \\
Not tight & $>200$ & $<2$ \\
\hline
\end{tabular}

In addition, the holding time of the workpiece is listed for which the workpiece can no longer be gripped. It is based on a final pressure of $400 \mathrm{mbar}$, a pressure of $800 \mathrm{mbar}$ at which the workpiece is dropped, and the assumption that the leakage is not compensated. The ranges of leakage show that the pressure rise method is sufficient, as other methods can measure leakage several orders of magnitude below the values listed in Table 1 [24].

Furthermore, the handling of flexible workpieces poses a danger as they change their shape significantly during the handling process $[25,26]$. If these protrude beyond the suction cups of the gripper system, there is a risk that the deflection of the workpiece will cause marginal gaps to form, which will promote 
second order leakage and ultimately lead to the tearing off of the workpiece [22].

Workpieces that allow first and third order leakage to occur are also risky to handle in a HRC application. Here the leakage is so high; the workpiece is almost immediately dropped.

This means the workpieces that can be used here have to be rigid as well as suction-tight.

\section{EXAMINATION OF LEAKAGE}

Figure 4 shows the different components of the handling process and their parameters that can influence the leakage. Preliminary examinations show that leakage of a closed vacuum gripping system where the suction cups are replaced by sealed plugs is $0,002 \mathrm{mbar} / \mathrm{s}$. Considering the values in Table 1 leakage of this magnitude is negligible.

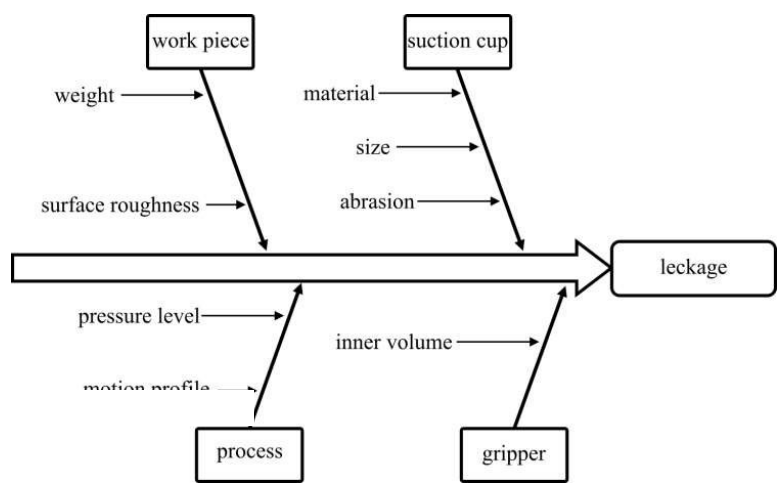

Figure 4: influence factors of leakage

Both the gripping system as a whole and the suction cup as a single component influence the leakage, depending on their characteristics. There are also influences from the workpiece, and characteristics of the handling process. The gripping system influences the leakage by the size of the internal volume, which is made up of the suction cups, hose lines and any fluidic reservoirs. Due to the variety of applications there are many types of suction cups which differ in properties such as material and the Shore hardness, geometric shape and diameter. It should be noted however, that in most cases a larger diameter is accompanied by a larger volume of the suction cup (see e.g. [27]). It is therefore more appropriate to consider the ratio of volume to circumference. The suction cups are also subject to wear, as they are in direct contact with the (rough) workpiece. This is therefore dependent on the number of load cycles. The workpiece has a surface roughness and a weight that influences the leakage.

If (9) is applied to the vacuum gripper system, the relationship between $t$ and $V$ in the range $p<800$ mbar can be described as follows:

$t \sim V$

In addition, the following relationship applies to $t$ and $d$ :

$t \sim \frac{1}{d^{2}}$

Or with the quadratic dependence of the area $A$ of the diameter $d$ :

$t \sim \frac{1}{A}$

If the quantity $d^{2}$ resulting from the opening of the container is transferred to the openings between the suction cup and the workpiece interface, the area $A$ can be described on the basis of the equations for the mean roughness value $\mathrm{Ra}$ as follows [28]:

$A=R a \cdot s=\int_{0}^{s}|y(x)| d x$ 
Whereby $y(x)$ describes the course of the surface profile in the direction of the coordinate $x$ over the length $s$ with the maximum expression $z$. This leads to the conclusion that there is the following relationship between $t$ and Ra:

$t \sim \frac{1}{R a}$

Moreover, it follows from equation (18) that $A \sim S$ which means that:

$t \sim \frac{V}{S}$

Where $s$ is the length of the circumference $U$ of the suction cup and the quotient $V / U$ is the ratio between volume and circumference of the suction cup. In addition, equation (9) shows the relationship:

$t \sim\left[\chi\left(\frac{p}{p_{0}}\right)-\chi\left(\frac{p_{\text {end }}}{p_{0}}\right)\right]$

so

$t \sim \chi\left(\frac{\Delta p}{p_{0}}\right)$

where:

$\chi\left(\frac{\Delta p}{p_{0}}\right) \sim \frac{p}{p_{0}}$

It therefore applies with equation (9):

$t \sim \Delta p$ für $p<800$ mbar

If the mass $m$ of the workpiece is considered in the form of the weight force $F_{G}$ with $m \cdot g=F_{G}$ and the context $p=F_{G} / A$

$t \sim m$

follows.

\subsection{Test Design and Setup}

First, the changes of the determined influencing factors of the leakage are examined in a onefactor-at-a-time test design. In the process the proportional correlations derived from the theoretical consideration are to be checked. The factors examined and their levels are shown in Table 2. The parameters highlighted in grey form the reference system. The remaining parameters with the expected non-linear or unknown correlation between pressure and time are determined by a completely factorial test design with 3 factors of 3 to 5 levels [29]. The structure of the test bench is shown in Figure 5. The workpiece (1) is positioned on a frame (2) in order to enable an approximately reproducible position of the workpiece parallel to the suction cups (3). The gripper consists of four suction cups, and is brought to the desired pressure level by the vacuum generator (4). The pressure is measured by a pressure sensor (5).

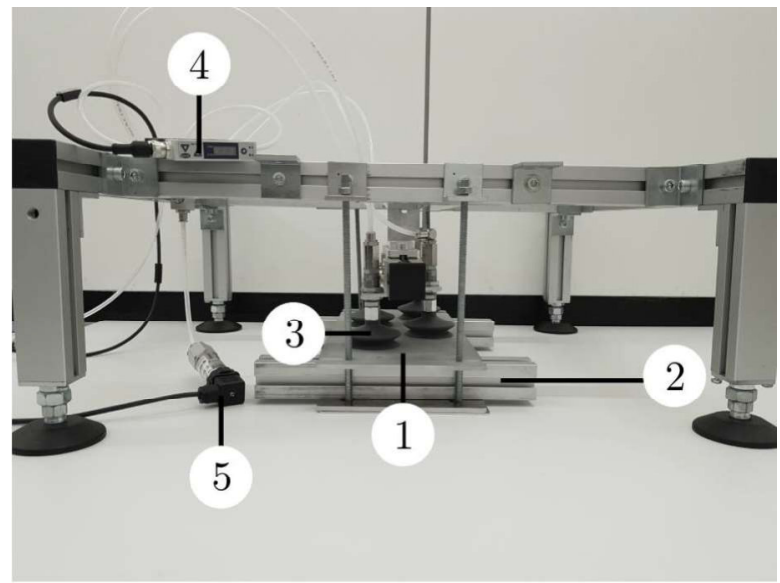

Figure 5: test bench for measuring leakage

\subsection{Test results of the one-factor-at-a-time test execution}

The test results for the individual parameters

Table 2: factors and levels of the one-factor-at-a-time design for the examination of leakage

\begin{tabular}{llccccc}
\hline \multirow{2}{*}{ factor } & unit & \multicolumn{5}{c}{ level } \\
\cline { 3 - 7 } & & 1 & 2 & 3 & 4 & 5 \\
\hline volume/circumference & $\mathrm{mm}^{3} / \mathrm{mm}$ & 53 & 89 & 153 & & \\
\hline abrasion & - & new & $50 \times P 220$ & $100 \times$ P220 & \\
\hline material & - & $\mathrm{NR}$ & $\mathrm{NBR}$ & $\mathrm{AU}$ & \\
\hline weight & $\mathrm{kg}$ & 1 & 2 & 3 & 4 & 5 \\
\hline surface roughness & $\mu \mathrm{m}$ & 0,3 & 2,5 & 5,7 & & \\
\hline volume & $\mathrm{ml}$ & 161 & 281 & 409 & 560 & 910 \\
\hline pressure level & $\mathrm{mbar}$ & 300 & 400 & 500 & 600 & 700 \\
\hline
\end{tabular}


examined are listed below. These are shown in Figure 6 including the theoretical linear approximation.
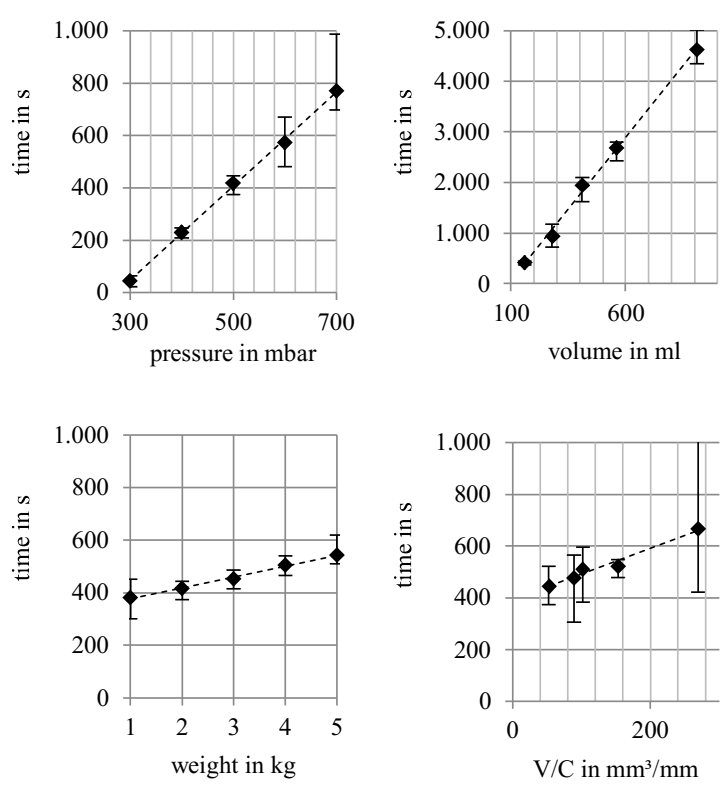

Figure 6: mean values and dispersion of the duration up to 800 mbar are reached as well as linear regression at different initial pressures (top left), different volumes (top right), the workpiece weight (bottom left) as well as the ratio of volume to circumference (bottom right)

Figure 6 (top left) shows the relationship between pressure level and ventilation time up to an absolute pressure of 800 mbar. It can be seen that this is approximately linear. The ventilation times of the system with different internal volumes also show a linear correlation between the ventilation time until 800 mbar is reached and the volume of the system (see top right). The same applies to the variation of the workpiece weight, where there is also an approximately linear correlation (see bottom left). Whereas here the effect is smaller compared to the previous factors. In the static state a change in the workpiece weight corresponds to a change in the differential pressure and therefore too results in a linear correlation. A variation in the ratio of volume to circumference of the suction cup also shows that a linear approximation of the relationship is possible (see bottom right). The effect is also comparatively small here.

The most likely reason for variation in all experiments is that the workpiece has a little tolerance in its positioning. This means that the suction cups have slightly different contact areas. Due to the marginally uneven surface of the workpiece this affects the leakage. It is noticeable that with increased compressible volume (see bottom right) there is a significant variation. A possible reason for this is the different roughness of the contact area in combination with the compressible volume. If the surface is smooth, leakage slowly increases pressure and volume leading to a ventilation time above average. If the surface is rough, leakage causes a fast increase of the volume to its maximum. After that, leakage causes a speeded pressure increase below average.

In order to be able to make tendentious statements regarding the influence of the roughness of the surface of the workpiece on the leakage, test specimens with surfaces with $\mathrm{Ra}$ values of $0,3 \mu \mathrm{m}$ (polished), 2,5 $\mu \mathrm{m}$ (smoothed) and $5,7 \mu \mathrm{m}$ (roughened) are examined. The results are shown in Figure 7 (top left).
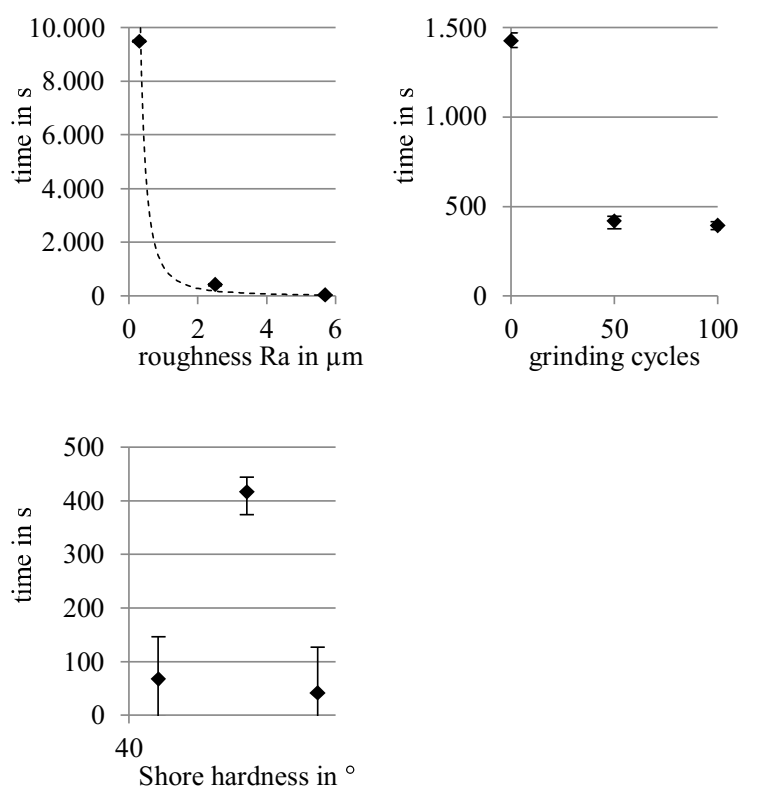

Figure 7: mean values and dispersion of the duration up to 800 mbar is achieved with different surface roughness of the workpiece (top left), wear conditions of the suction cup (top right) as well as suction cup materials (bottom left)

It can be seen that the ventilation times here differ by several orders of magnitude and a hyperbolic approximation (dashed curve) can therefore be suitable. In order to make an initial statement regarding the wear condition it is 
simulated using abrasive paper with a grain size of P220. For this purpose 50 sanding strokes per suction cup are performed for the slightly worn condition and 100 sanding strokes per suction cup are performed for the heavily worn condition. For the condition as good as new there is no treatment by the abrasive paper. The measurements in Figure 7 (top right) show that abrasion significantly reduces the ventilation time.

Suction cup materials that are suitable not only for a specific material, but also universally for suction-tight and rigid workpieces are investigated. The ventilation curves for different suction cup materials are shown in Figure 7 (bottom left), whereby the suction cup materials have the following Shore hardness: NR $45^{\circ}$, NBR $60^{\circ}$ and $\mathrm{AU} 72^{\circ}$. It can be seen that the material selection has a large influence on the ventilation time.

\subsection{Test results of the full factorial test procedure}

The previous experiments show that non-linear relationships exist between time and the factors surface roughness, wear condition, and material of the suction cup according to the findings of the experiments in the previous section. These influences are therefore investigated on the basis of a completely factorial test procedure. The test setup is identical to the previous tests. In order to investigate different surface roughness, the test workpieces are sandblasted with different grain sizes. The different $\mathrm{Ra}$ values as well as the different amount of load cycles applied on the suction cups and the materials used are shown in Table 3. Here the load cycles are applied via compression and decompression of the section cups and therefore show way less abrasion compared to the sanded suction cups from the previous section.

Table 3: factors and levels of the full factorial test design for the examination of leakage

\begin{tabular}{l|cccccccc}
\hline \multirow{2}{*}{ factor } & \multicolumn{1}{|c}{ level } \\
\cline { 2 - 8 } & 1 & 2 & 3 & 4 & 5 & 6 & 7 & 8 \\
\hline load cycles & $10^{2}$ & $10^{3}$ & $10^{4}$ & $10^{5}$ & $10^{6}$ & & & \\
material & $\mathrm{NR}$ & $\mathrm{NBR}$ & $\mathrm{AU}$ & & & & & \\
$\begin{array}{l}\text { roughness in } \\
\mu \mathrm{m}\end{array}$ & 0,3 & 1,44 & 1,73 & 1,94 & 2,45 & 3,11 & 4,8 & 6,07 \\
\hline
\end{tabular}

In the following the test results are presented separately according to the different suction cup materials. Figure 8 to Figure $\mathbf{1 0}$ show the time durations up to 800 mbar depending on the surface condition and the load cycles. At least with regard to surface roughness, there is a clear tendency to recognize that the ventilation time decreases with increasing Ra value. The number of load cycles on the other hand influences the molecular structure of the suction cups and is thus also influenced by the material. No clear tendencies can be identified here.

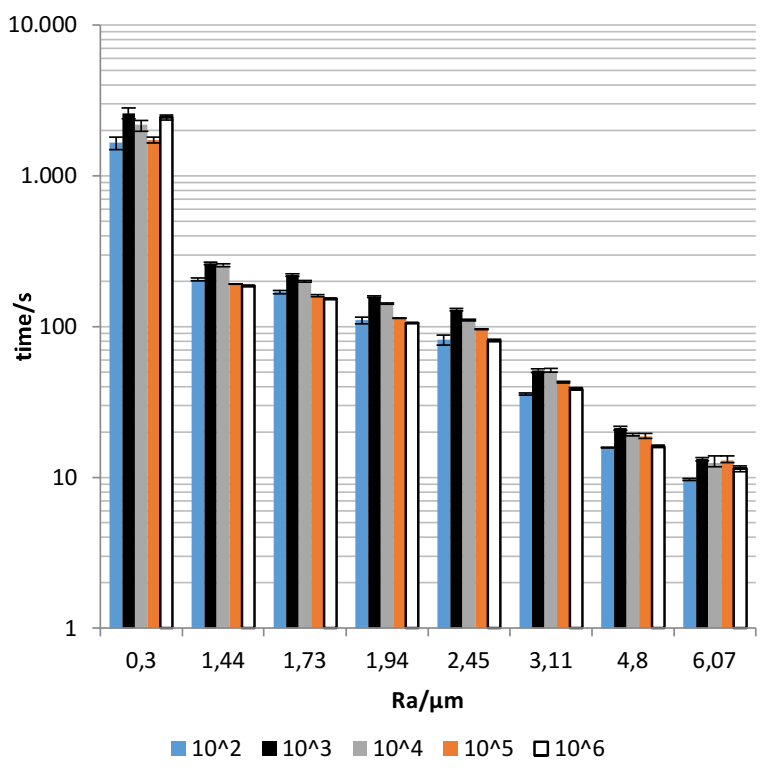

Figure 8: ventilation times for different degrees of surface roughness and load cycles for NR

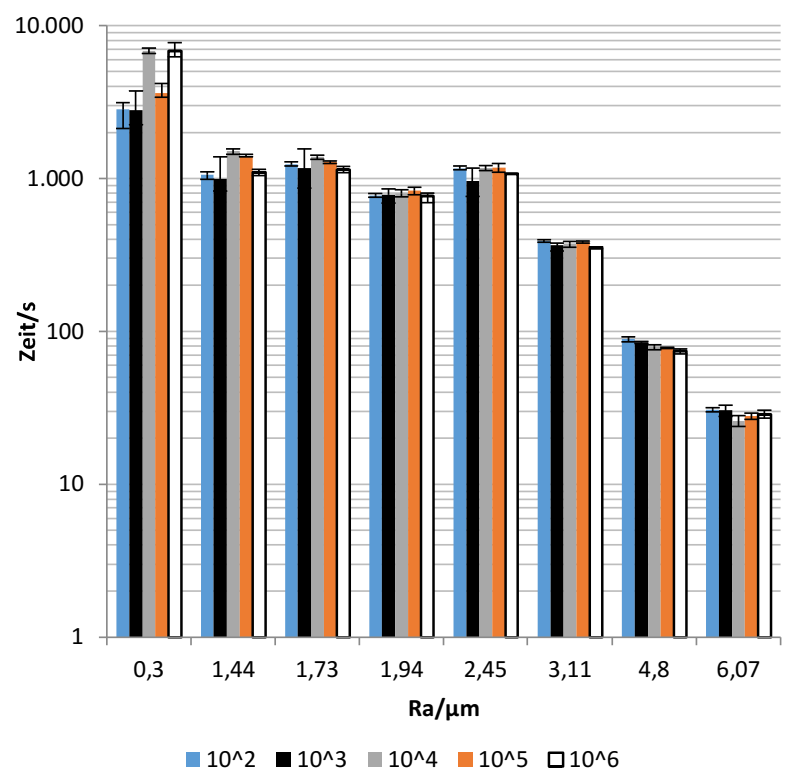

Figure 9: ventilation times for different degrees of surface roughness and load cycles for NBR 


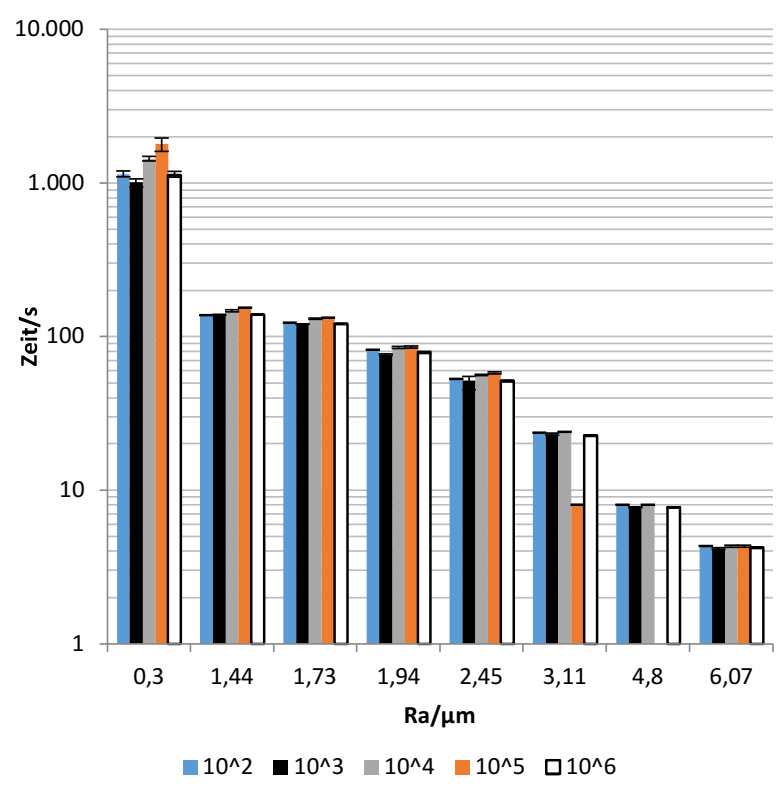

Figure 10: ventilation times for different degrees of surface roughness and load cycles for AU

\subsection{Discussion}

The measurements show that the theoretically determined linear relationships between individual influencing parameters and the ventilation time up to 800 mbar are appropriate. Consequently, the ventilation time can be regarded as proportional to the internal volume, the ratio of volume and circumference of the suction cup, the pressure difference and the workpiece weight. The completely factorial tests show that the relationships between ventilation duration and surface roughness, number of load cycles and suction cup material cannot be clearly described mathematically and thus have to be measured separately for every single application.

\section{SUMMARY AND OUTLOOK}

This paper presents new theoretical and experimental examinations of leakage in vacuum gripping systems. They fill the gap between state of the art design methods for such systems and the need for safety in case of an energy failure.

The theoretical and experimental examinations of the impact factors and effects of leakage show that some of the identified factors correlate linear with the ventilation time. Others do not but their effects are also shown in this paper.
These results can be used as a basis to design vacuum gripping systems in order to obtain the lowest leakage possible. Thereby the compensation of leakage can only be temporary, and the duration of this compensation has to be determined long enough to transfer the workpiece to a safe state.

Further examinations can include more factors like different suction cup materials and differently shaped workpieces. This can give an additional understanding of the effect on leakage and makes the design of vacuum gripping systems based on leakage suitable for more applications.

\section{NOMENCLATURE}

$\begin{array}{ll}A & \text { Area } \\ A U & \text { polyester-urethane rubber } \\ C & \text { circumference } \\ d & \text { diameter } \\ L & \text { leakage } \\ m & \text { mass } \\ N B R & \text { Nitrile rubber } \\ N R & \text { natural rubber } \\ p & \text { pressure } \\ p_{0} & \text { ambient pressure } \\ s & \text { length } \\ t & \text { time } \\ V & \text { Volume }\end{array}$

\section{REFERENCES}

[1] Hesse, S., 2011. Greifertechnik: Effektoren für Roboter und Automaten. Hanser, München.

[2] Grubba, M.-A., 2002. Untersuchungen zum Kraftübertragungsverhalten von Vakuumgreifsystemen für Hohlkörper. Universität Dortmund.

[3] Schmalz, J., Giering, L., Hölzle, M., Huber, N. et al., 2016. Method for the Automated Dimensioning of Gripper Systems 44, p. 239.

[4] Schmierer, G., 2001. Ein modulares Baukastensystem für Kletterroboter nach dem Gleitrahmenprinzip. Jost-Jetter, Heimsheim.

[5] Sdahl, M., 2006. Beitrag zum autonomen Dreipunkt-Sauggreifen.

[6] Daimler AG, 2017. Mercedes-Benz Cars: Der Rohbau der Zukunft ist flexibel. 
[7] Demtröder, W., 2018. Experimentalphysik 1. Springer Berlin Heidelberg, Berlin, Heidelberg.

[8] Festo. Grundlagen der Vakuumtechnik, Kurzübersicht - Einführung.

[9] Jodin, D., 1991. Untersuchungen zur Handhabung von biegeweichen Flächenzuschnitten aus Leder mit pneumatischen Greifern, Dortmund.

[10] Edelmann, C., 1998. Vakuumphysik: Grundlagen, Vakuumerzeugung und messung, Anwendungen. Spektrum Akad. Verl., Heidelberg.

[11] Fritz, F., 2017. Ein Modell zur energetischen Analyse und Bewertung von Vakuum-Greifsystemen, 1st edn. Shaker, Herzogenrath.

[12] Tiwari, A., Persson, B.N.J., 2019. Physics of suction cups.

[13] Tiwari, A., Persson, B.N.J., 2019. Theory for diffusive and ballistic air leakage and its application to suction cups.

[14] Li, L., Li, K., Zhao, Z., Wang, H. et al., 2015. A Novel Test Method of Low Leakage Rate of MEMS Vacuum Packaging, in Proceedings of the 10th IEEE International Conference on Nano/Micro Engineered and Molecular Systems (IEEENEMS), IEEE, [Piscataway, New Jersey], p. 175.

[15] Umrath, W. Grundlagen der Vakuumtechnik, Köln.

[16] Jousten, K., Editor, 2013. Wutz Handbuch Vakuumtechnik, 11th edn. Springer Vieweg.

[17] Deutsches Institut für Normung e.V. Zerstörungsfreie Prüfung Dichtheitsprüfung: Prüfgasverfahren, Berlin. Beuth Verlag 19.100, 2011(13185).

[18] Deutsches Institut für Normung e.V. Zerstörungsfreie Prüfung -

Dichtheitsprüfung -

Druckänderungsverfahren, Berlin. Beuth Verlag 19.100, 2001(13184).

[19] Wutz, M., Adam, H., Walcher, W., 1992. Theorie und Praxis der Vakuumtechnik: Mit 74 Tabellen, 5th edn. Vieweg, Braunschweig u.a.

[20] Baehr, H.D., Kabelac, S., 2012. Thermodynamik: Grundlagen und technische Anwendungen, 15th edn.

[21] Seegräber, L., 1993. Greifsysteme für Montage, Handhabung und
Industrieroboter: Grundlagen - Erfahrungen - Einsatzbeispiele. Expert-Verl., Ehningen bei Böblingen.

[22] Götz, R., 1991. Strukturierte Planung flexibel automatisierter Montagesysteme für flächige Bauteile. Springer, Berlin u.a.

[23] J. Schmalz GmbH, 2016. SXPi/SXMPi: Betriebsanleitung, Glatten.

[24] Deutsches Institut für Normung e.V. Zerstörungsfreie Prüfung - Dichtheitsprüfung: Kriterien zur Auswafil von Prüfmethoden und verfafiren, Berlin. Beuth Verlag 19.100, 1999(1779).

[25] Fantoni, G., Santochi, M., Dini, G., Tracht, K. et al., 2014. Grasping devices and methods in automated production processes 63, p. 679.

[26] Shchekutin, N., Bouzakis, A., Overmeyer, L., Shkodyrev, V., 2014. Handling concept for ultra-thin glass sheets.

[27] J. Schmalz GmbH, 2017. VakuumKomponenten: Katalog 2016/2017, Glatten.

[28] Grote, K.-H., Feldhusen, J., 2011. Dubbel. Springer Berlin Heidelberg, Berlin, Heidelberg.

[29] Kleppmann, W., 2013. Versuchsplanung: Produkte und Prozesse optimieren, 8th edn. Hanser, München. 